\title{
A PETROBRÁS E AS REFORMAS DO SETOR DE PETRÓLEO E GÁS NO BRASIL E NA ARGENTINA ${ }^{1}$
}

\author{
Pablo Gabriel Ferreira
}

\begin{abstract}
RESUMO
A consolidação da Petrobras enquanto companhia transnacional ocorre em um momento de intensificação do processo de internacionalização das empresas brasileiras. Uma das características dos investimentos internacionais de países em desenvolvimento é que eles se concentram em sua própria região. Esse é o caso do Brasil, que destina uma parte importante de seus investimentos no exterior à América do Sul, especialmente à Argentina, onde o Brasil tornou-se um dos maiores investidores estrangeiros. A Petrobras Energía S.A., subsidiária da estatal brasileira e segunda maior empresa petrolífera do país vizinho, tornou-se um ator econômico importante, com atividades em todos os segmentos do setor energético. O objetivo deste artigo consiste em analisar os investimentos da Petrobras na Argentina, entre 2000 e 2005, seu contexto e suas motivações. Para isso, avaliamos a relação entre o processo de internacionalização da empresa e as reformas do setor de petróleo e gás em ambos os países. Constatamos que as vantagens institucionais de localização motivaram a Petrobrás a eleger a Argentina como base de suas atividades na região: do ponto de vista das regras formais, o país proporcionava um ambiente institucional favorável aos investimentos estrangeiros, já que desde o início do projeto de reforma do setor de petróleo e gás argentino, a idéia central era de internacionalizá-lo, permitindo a entrada e saída de empresas estrangeiras e expondo o mercado interno ao mercado internacional.
\end{abstract}

PALAVRAS-CHAVE: Economia Política internacional; companhias transnacionais; Petrobrás; reformas do setor de petróleo e gás; relações Brasil-Argentina.

\section{INTRODUÇÃO}

Em janeiro de 1998, entra em vigor no Brasil a Lei n. 9 478, aprovada no dia 6 agosto de 1997 (BRASIL. Presidência da República, 1997). Com a aprovação dessa lei, conhecida como a "Lei do Petróleo", o setor de petróleo e gás no Brasil passa por uma profunda transformação. A Lei prevê reformas significativas, entre elas a quebra do monopólio dos hidrocarbonetos, exercido pela Petróleo Brasileiro S/A (Petrobrás), desde sua criação, em 1953, transferindo a gestão da política dos hidrocarbonetos à União (Arts. $3^{\circ}$ e $4^{\circ}$ ). Criase o Conselho Nacional de Política Energética, "vinculado à Presidência da República e presidido pelo Ministro de Estado de Minas e Energia” (Art. $2^{\circ}$ ). Esse órgão substitui o antigo Departamento Nacional de Combustíveis (DNC). O setor de pe-

\footnotetext{
${ }^{1}$ Este artigo é parte da Dissertação de Mestrado Petrobrás na Argentina (2000-2005) : internacionalização e políticas governamentais, apresentada ao Programa de Pós-Graduação em Relações Internacionais, da Universidade Federal Fluminense (UFF), em 2008.
}

tróleo e gás passa a ser administrado por uma agência reguladora, a Agência Nacional do Petróleo, Gás Natural, e Biocombustíveis (ANP), “entidade integrante da Administração Federal Indireta, submetida ao regime autárquico especial, [...] vinculada ao Ministério de Minas e Energia” (Art. $7^{\circ}$ ). Muitas das atribuições antes exercidas pela Petrobrás foram transferidas à ANP.

A principal mudança promovida no setor pela nova Lei, entretanto, foi a abertura à concorrência. A partir de então, a Petrobrás passou a competir com empresas nacionais e estrangeiras em todas as fases da cadeia produtiva: na exploração, na produção, no refino, no transporte e na distribuição. O Art. 32, da Lei n. 9 478/97, determina que a Petrobrás terá "seus direitos sobre cada um dos campos que se encontrarem em efetiva produção", transferindo a administração dos demais campos à ANP, exceto se comprovada a capacidade financeira para continuar as atividades de exploração (Art. 33). Uma vez feita a transferência de titularidade dos blocos, a ANP realiza, em junho de 1999, a primeira licitação de áreas para exploração, da qual participaram todas as grandes 
companhias internacionais de petróleo (BRASIL ENERGIA, 1999a, p. 16-17). O segundo leilão ocorre em julho do ano seguinte. Em ambos, a Petrobrás ficou com a maior parte dos poços. Em 2000, ela foi responsável por 35\% dos investimentos em bônus e ficou com 30,7\% das áreas, o que a colocou largamente à frente de grandes concorrentes internacionais, do porte da Chevron e da Shell (BRASIL ENERGIA, 2000, p. 28).

\section{A PETROBRÁS E A REFORMA DO SETOR DE PETRÓLEO E GÁS NO BRASIL}

Com a reforma do setor de petróleo e gás, a Petrobrás viu-se diante de uma nova realidade. Agora ela teria de concorrer com poderosas empresas transnacionais no mercado nacional, inclusive com as majors, tais como Exxon Mobil, Shell, British Petroleum, Texaco, entre outras gigantes. Diante das novas circunstâncias, a Petrobrás pôs em prática um amplo programa de reforma administrativa, no qual se previa uma revisão do modelo organizacional. Dentre as medidas, estava prevista a criação de cinco unidades de negócios: Exploração e Produção (no Brasil); Abastecimento (que compreende as atividades de refino, comercialização, transporte e petroquímica); Distribuição; Gás e Energia; e Internacional: “A idéia chave da nova estrutura organizacional [e] [d]a criação de unidades de negócios [...] [consiste em] sustentar as metas de expansão, rentabilidade, produtividade e internacionalização" (PETROBRÁS, 2001).

Em abril de 1999, o então Ministro de Minas e Energia, Rodolpho Tourinho, nomeia para a Presidência da Petrobrás o economista Henri-Philippe Reichstul. Três meses após sua posse, o novo Presidente da estatal promove uma ampla mudança nas superintendências e diretorias da empresa (BRASIL ENERGIA, 1999a, p. 22). Em outubro do mesmo ano, é divulgado o Plano Estratégico 2000-2010, que estabelece as novas diretrizes da Petrobrás: "O Plano Estratégico 2000-2010 do Sistema Petrobrás [...] representa um referencial para a inserção da Petrobrás num ambiente competitivo pautado na profunda análise das oportunidades de negócios no Brasil e no exterior. Nele estão definidas as diretrizes de negócio e de gestão que irão nortear as atividades da Petrobrás até 2010, objetivando seu crescimento, maior rentabilidade, consolidação da posição de liderança no Brasil e ampliação de sua presença no mercado internacional” (PETROBRÁs, 2000).
As orientações estabelecidas no Plano Estratégico imprimiam um novo perfil à empresa. A Petrobrás deixa de ser a executora do monopólio do petróleo e amplia seu escopo visando tornarse "uma empresa de energia com forte presença internacional e líder na América Latina” (PETROBRÁS, 2002, p. 4). A companhia aumentava deste modo a abrangência de sua atuação, estendendo suas atividades para outros segmentos do setor energético além do petróleo e gás, tais como geração, transmissão e distribuição de eletricidade. Segundo o então gerente do Serviço de Planejamento da Petrobrás (Serplan), Celso Fernando Lucchesi (1999-2000), "a meta de transformar a empresa em uma companhia integrada de energia visa a capacitá-la a prover soluções energéticas, através da geração térmica [...] que utilize o petróleo ou o gás natural produzido pela estatal”. De acordo com Lucchesi, "a idéia é que, na ponta da distribuição, a Petrobrás venda produtos de energia” (BRASIL ENERGIA, 1999b, p. 22-23).

Além de tornar-se uma empresa integrada de energia, o Plano Estratégico 2000-2010 previa a transformação definitiva da Petrobrás em uma companhia transnacional. De fato, a partir de 1999, a internacionalização passou a ser o foco central das atividades da empresa. Até o final da década de 1990, as atividades internacionais da Petrobrás eram exercidas por uma subsidiária. A partir da reforma administrativa, aprovada em abril de 2000, cria-se a Unidade de Negócios Internacionais, vinculada à Presidência da estatal. Por decisão da Assembléia Geral Extraordinária, realizada no dia 30 de setembro de 2002, a Petrobras Internacional S.A. (Braspetro), antes encarregada de exercer as atividades internacionais da Petrobrás, é incorporada à diretoria de negócios internacionais (PETROBRÁS, 2003a, p. 52). Segundo o então diretor de negócios internacionais da empresa, Jorge Camargo, esta medida foi um divisor de águas para o processo de internacionalização da Petrobrás (UM NEGÓCIO DA CHINA, 2002, p. 150-151).

Antes mesmo que as medidas previstas no Plano Estratégico 2000-2010 entrassem em vigor, no início de 2000, a estatal deu os primeiros passos na direção dos objetivos previstos no documento. No final de 1999, a empresa compra duas refinarias na Bolívia, pertencentes à estatal boliviana Yacimientos Petroliferos Fiscales de Bolivia,YPFB (BRASIL ENERGIA, 1999b, p. 23). Este investi- 
mento ia ao encontro do objetivo de expandir o refino de petróleo no exterior, além de contemplar o foco de atuação da empresa na América Latina.

Durante os primeiros anos da década de 2000, os investimentos internacionais da Petrobrás, concentraram-se na América do Sul, principalmente na Bolívia e na Argentina. As duas refinarias adquiridas na Bolívia foram o início de uma série de aquisições em países vizinhos. Em 2000, a Petrobrás entra com 34\% do capital da Companhia binacional Mega (PETROBRÁS, 2001). Com um investimento no valor de US\$ 715 milhões, o empreendimento foi feito em parceira com a Yacimientos Petrolíferos Fiscales (YPF) (38\%) e a Dow Chemical (28\%) (ibidem). Em dezembro do ano seguinte, a Petrobrás e a Repsol-YPF fecham um acordo definitivo sobre a troca de ativos no valor de US\$ 500 milhões (PETROBRÁS, 2002, p. 39). Por este acordo, a Petrobrás adquire 99,5\% da empresa EG3, compreendendo uma refinaria e 700 postos de gasolina na Argentina: "Esta operação é de grande importância estratégica para a Petrobrás. Neste sentido, vale ressaltar os seguintes pontos: [1] a Petrobrás está adquirindo imediatamente cerca de $12 \%$ do mercado de combustíveis da Argentina, o segundo maior mercado e economia da América do Sul depois do Brasil. [2] A sinergia e complementaridade dos ativos da Petrobrás nas regiões sul/sudeste do Brasil e na Bolívia, com os ativos que estão sendo adquiridos na Argentina. [...] Esta operação representa um grande passo na realização de sua estratégia de internacionalização, focada na expansão de atividades na América Latina” (ibidem).

Em vista do plano de tornar-se uma empresa integrada de energia com liderança na América Latina, a Petrobrás realiza, no ano de 2002, três importantes operações de aquisição, todas elas na Argentina. A primeira delas foi a compra da Petrolera Santa Fe, então pertencente à Devon Energy Corporation, pelo valor de US\$ 89,5 milhões (PETROBRÁS, 2003a, p. 52-53). Mas a operação mais importante foi a compra de duas companhias do grupo Pérez Compac, segunda maior petroleira da Argentina e maior companhia independente da América Latina. Em uma operação de US\$ 1,03 bilhão, a estatal brasileira adquire, no mês de outubro de 2002, 58,62\% da Pérez Compac S.A., "sendo US\$ 689 milhões pagos à vista, e US\$ 338 milhões em notas com juros anuais de $4,75 \%$ e vencimento final em 2007" (ibidem). Além desta operação, a Petrobrás compra, "mediante pagamento à vista de US\$ 49,8 milhões, uma participação de 39,67\% na Petrolera Pérez Compac S.A” (ibidem). Em maio de 2003, a Comisión Nacional de Defensa de la Competencia, órgão do governo argentino encarregado de regular a concorrência, aprova a operação. Estas aquisições foram um passo fundamental na direção dos objetivos do Plano Estratégico 2000-2010. Com a compra da Pérez Compac (Pecom), a Petrobrás consolida sua posição de empresa integrada de energia com liderança na América Latina.

As aquisições realizadas entre 1999 e 2002 confirmam o foco dos investimentos internacionais da estatal na Argentina e na Bolívia, conforme as diretrizes estabelecidas no Plano Estratégico. Os relatórios anuais de 2002 e 2004 mostram que, de todos os países em que a Petrobrás tem investimentos, apenas na Argentina e na Bolívia ela atua em toda a cadeia produtiva, do poço ao posto. Em 2004, é aprovada a fusão de todos os ativos da Petrobrás na Argentina, compreendendo a EG3, a Petrolera Santa Fe, a Petrobrás Argentina e a Pecom, criando-se uma única empresa: a Petrobrás Energía S. A., PESA (PETROBRÁS, 2005, p. 56). A partir dessa fusão, a Petrobrás Energía S.A. torna-se o braço internacional da Petrobrás e a Argentina, a base da expansão das atividades da estatal na América do Sul.

\section{A PETROBRÁS NAARGENTINA}

A presença da Petrobrás na Argentina remonta à década de 1980. A primeira tentativa de investir na Argentina teve uma motivação política. Com a redemocratização brasileira e argentina, houve uma aproximação entre os governos democráticos dos dois países. A partir 1985, os presidentes do Brasil, José Sarney, e da Argentina, Raúl Alfonsín, engajam-se em um projeto de integração entre os dois países. Assim, é assinada em novembro deste ano a Declaração de Iguaçu, "que constitui a Comissão Mista Binacional de Alto Nível para acelerar o processo de integração bilateral. Mais um passo foi dado com a criação do Programa para Integração e Cooperação Econômica, em julho de 1986” (HERZ \& HOFFMANN, 2004, p. 201). É nesse contexto que surge o primeiro esboço para o processo de integração energética entre o Brasil e a Argentina. A Petrobrás, seguindo as determinações do governo, teria um papel importante neste 
processo, conforme consta em seu relatório anual de 1986: "Há oportunidades de joint venture, abertas na Argentina, para a construção de gasodutos e instalações industriais, como decorrência do Protocolo $\mathrm{N}^{\circ} 8$ - Energia, da Ata de Integração Argentino-Brasileira assinada pelos presidentes dos dois países” (PETROBRÁS, 1987, p. 29).

Os primeiros investimentos em exploração e produção, no entanto, só foram realizados na década seguinte. Em 1990, a Petrobrás inicia suas primeiras atividades de exploração na Argentina, "através de um estudo geopotencial e do reprocessamento de 267 quilômetros de linhas sísmicas da bacia San Julian Marina" (PETROBRÁs, 1991, p. 41). Dois anos depois, a Braspetro (subsidiária internacional) e a BR (subsidiária de distribuição) assinam um acordo de associação visando o mercado de distribuição de derivados na Argentina, “o que será feito através de uma subsidiária [da Braspetro], em fase de constituição naquele país” (PETROBRÁS, 1994, p. 28). Em 1997, a Braspetro adquire direitos de exploração no bloco Puesto Zuñiga, na Bacia de Neuquén. No mesmo ano, iniciam-se as negociações entre a Petrobrás, a YPF e a Dow Chemical para a criação da companhia Mega S. A., que seria responsável pelo "processamento de $36 \mathrm{mi}$ lhões de metros cúbicos por dia de gás natural na Argentina” (PETROBRÁS, 1998, p. 5).

Além desses empreendimentos, é lançado o projeto de construção de um gasoduto ligando a Argentina ao Rio Grande do Sul: "[Com o objetivo de pôr em prática o projeto, a Petrobrás firma acordo] com a Companhia Estadual de Energia Elétrica do Rio Grande do Sul, a Yacimentos Petrolíferos Fiscales (YPF), a Transportadora de Gás del Norte (Argentina), a Companhia de Gás do Rio Grande do Sul (Sulgás) e a AES Energy, dos Estados Unidos, para suprimento de 2,5 milhões de metros cúbicos por dia de gás natural para uma unidade termelétrica de 450 MW a ser construída em Uruguaiana (RS), com a construção de um gasoduto de 440 quilômetros de extensão da Argentina para a fronteira brasileira [...]” (ibidem).

Durante a década de 1990, havia a expectativa de importação de gás natural da Argentina. Além deste consórcio, outros grupos argentinos mantinham negociações com a Petrobrás, tendo em vista o fornecimento de gás natural ao Brasil: "Um desses grupos é o consórcio ABGP, formado pela argentina Emprigas, a canadense Alberta Energy, a japonesa Marubeni e a australiana Ampolex, que quer instalar um gasoduto entre a província argentina de Salta (ao norte) e o sul do Brasil, podendo entrar pelo Paraná ou Rio Grande do Sul” (BRASIL ENERGIA, 1996, p. 33).

Por parte do Brasil, havia uma demanda pelo gás natural argentino. Com a construção de usinas termelétricas em São Paulo (Paulínia e Piratininga), o gás vindo da Bolívia não seria suficiente para atender às necessidades do Estado. Em vista desse problema, a então Presidente da Companhia de Gás de São Paulo (Congás), Iêda Correia Gomes (1997), declara que a Companhia cogita a possibilidade de importar gás natural da Bacia do Noroeste, situada na Argentina (BRASIL ENERGIA, 1997, p. 28-29). O transporte seria feito por meio do Gasoduto do Mercosul, que na época ainda encontrava-se em fase de desenvolvimento (ibidem).

Além do estado de São Paulo, o Rio Grande do Sul também tinha interesse em obter fornecimento de gás natural da Argentina. Lideranças políticas e empresariais gaúchas pressionavam a Petrobrás a lançar o edital de construção de um gasoduto que traria o gás do norte da Argentina para os estados do Sul do Brasil, passando pela cidade de Uruguaiana: "O projeto Fronteira Sul, como [era] chamado [o gasoduto], começaria na cidade argentina de Aldeia Brasileira, na província de Entre Rios, teria no total 3.100 quilômetros de extensão, levando o produto até São Paulo. [...] O investimento global seria de US\$1,5 bilhão. Um consórcio foi criado [em 1997] para a realização da obra, liderado pela Petrobrás e a argentina Yacimentos Petroliferos Fiscales (YPF), privatizada em 1993. [...]”. Segundo o chefe do Setor Técnico e Operacional da Sulgás, José Freire, "A YPF vai construir o trecho de 440 quilômetros, dentro do território de seu país, de Aldeia Brasileira até a fronteira com o Brasil. Os 10 quilômetros até a Usina Térmica da AES, em Uruguaiana, serão construídos pela Sulgás. A empresa argentina Transportadora de Gás del Norte (TGN) cuidará do transporte do combustível até a fronteira, transferindo dali em diante a responsabilidade para a Petrobrás e a [Sulgás]" (BRASIL ENERGIA, 1998, p. 17).

Foram criados, em 1999, dois consórcios para a realização de estudos de viabilidade de transporte de gás natural da Argentina até a cidade de Porto Alegre (RS). Um formado pelas empresas 
Petrobrás, YPF e Total; e outro formado pela British Gas, Pan American e Ancap (BRASIL ENERGIA, 1999c, p. 36-38). O grande salto dos investimentos da Petrobrás na Argentina, contudo, ocorre após a reforma do setor de petróleo e gás no Brasil, em 1998, e a conseqüente reestruturação da empresa brasileira na virada do século. A Argentina teve uma posição importante para a execução das diretrizes estabelecidas no Plano Estratégico 2000-2010. A criação da Mega S.A., em consórcio com a YPF e a Dow Chemical, foi o início de uma série de investimentos da Petrobrás realizados no país vizinho. A troca de ativos com a Repsol-YPF, no valor de US\$ 500 milhões, realizada em 2001, confirmou essa tendência.

Conforme visto na seção anterior, o ano de 2002 foi histórico para o processo de internacionalização da Petrobrás e para suas atividades na Argentina. Além de lançar ações preferenciais (sem direito a voto) nas bolsas de Nova York (2001) e Madrid (2002), com a compra da Petrolera Santa Fe, ao preço de um dólar por barril, a Petrobrás aumenta sua produção em 11 mil barris de óleo equivalente por dia (boe/d), acrescentando 84,7 milhões de barris às suas reservas internacionais (UM NEGÓCIO DA CHINA, 2002, p. 152).

A principal aquisição de 2002, entretanto, foi a empresa argentina de energia Pérez Compac (Pecom). A agência de análise britânica Wood Mackenzie avaliou a operação, no valor de US\$ 1,2 bilhão, como um bom negócio (ibidem). A compra da Pecom coloca a Petrobrás mais perto das metas de internacionalização fixadas no Plano Estratégico 2000-2010. O então presidente da estatal, Francisco Gros, em sua mensagem aos acionistas, declara que "a partir de agora [2002], podemos, sem medo de errar, nos referir à Petrobrás como uma verdadeira multinacional verde e amarela” (PETROBRÁS, 2003a, p. 9).

Os investimentos no exterior realizados pela Petrobrás no ano de 2002 atingiram um valor recorde. Desde a reestruturação da empresa, em 1998, até 2002, ela investiu cerca de US\$ 500 milhões ao ano fora do Brasil. No ano de 2002, o valor dos investimentos saltou para US $\$ 2$ bilhões, o que equivale ao quádruplo do ano anterior (PETROBRÁS, 2003b). Cerca de 60\% desse valor foram destinados à Argentina.
As novas aquisições da empresa possibilitaram uma elevação da produção no exterior de 57 mil boe/d para 250 mil boe/d (UM NEGÓCIO DA CHINA, 2002, p. 150), ou seja, quase cinco vezes mais: "Com a aquisição da Pérez Compac, na Argentina, e a incorporação de seus ativos, as reservas provadas da Petrobrás chegaram a 11,6 bilhões de barris de óleo equivalente" (PETROBRÁS, 2004, p. 4). Com isso, "a soma da produção no Brasil e no exterior atingiu 2.036 mil boe/d, o que situa a Petrobrás no seleto clube de empresas que produzem mais de 2 milhões de barris por dia” (ibidem). Não somente a estatal amplia suas reservas e sua produção de óleo, mas também incrementa sua capacidade de refino no exterior, que a partir de então atinge 134 mil barris por dia (idem, p. 119). Segundo o ex-Diretor de negócios internacionais, Nestor Cerveró (2003), "na Argentina, ao comprarmos a segunda companhia de óleo e energia do país, passamos a ter uma atividade maior que no resto do mundo" (BRASIL ENERGIA, 2003, p. 107-109).

Ao comprar a Pérez Compac, a Petrobrás passa imediatamente a atuar em mais três países da América do Sul: Equador, Venezuela e Peru, onde a empresa argentina já possuía ativos. Em 2003, a estatal estava presente em seis países do continente - Argentina, Bolívia, Colômbia, Equador, Peru e Venezuela - tornando mais próxima sua meta de liderança na América Latina.

Na verdade, a Petrobrás põe em prática na Argentina duas orientações de seu Plano Estratégico. Em primeiro lugar, tornar-se uma empresa integrada de energia; em segundo, ser uma companhia líder na América Latina. Além de ampliar sua atuação no continente, ela passa a atuar em toda a cadeia do setor energético. No que diz respeito à cadeia petrolífera, ela mantém atividades em exploração, produção, transporte, refino e distribuição. Com a compra da Pecom, a Petrobrás torna-se efetivamente uma empresa integrada de energia, visto que a companhia argentina já atuava em outros segmentos do setor energético. A incorporação dos ativos da petrolífera argentina e a criação da Petrobrás Energía S.A. (PESA), em 2004, fizeram da estatal proprietária de cinco unidades petroquímicas, uma rede de oleodutos e gasodutos, de participação na Transportadora de Gas del Sur (TGS), na Transener (empresa de transmissão e distribuição de eletricidade), duas hidrelétricas e participação na Genelba (responsá- 
vel por $10 \%$ da energia elétrica do país). Todo esse complexo faz da Petrobrás Energía um ator de grande importância no setor energético da Argentina e a segunda maior empresa integrada do setor petrolífero (do poço ao posto) naquele país.

\section{POR QUE AARGENTINA?}

Com a criação da PESA, a Argentina tornouse a base das atividades internacionais da Petrobrás na América do Sul. Não é por acaso que os relatórios anuais da Petrobrás Energía resumem as atividades da empresa em todos os países em que está presente no continente (Argentina, Bolívia, Colômbia, Equador, Peru e Venezuela), sem, no entanto, fazer distinção entre nacional e internacional (PETROBRÁS ENERGÍA S.A., 2006). Seguindo as orientações do Plano Estratégico 20002010, a Petrobrás tornou-se efetivamente, por intermédio da PESA, "a empresa integrada de energia do Cone Sul”, para usar uma expressão empregada pela Comissão Econômica para a América Latina e o Caribe (CEPAL) em seu relatório sobre as transnacionais da América Latina - as "translatinas" (CEPAL, 2005, p. 100). Com atuação em todos os países produtores de petróleo e com atividades em todos os segmentos do setor, a PESA faz jus à expressão empregada pela Cepal: "As atividades de refino e distribuição no exterior, com cinco refinarias, que mantêm capacidade nominal de 135,4 mil barris por dia, e 830 postos de serviço na Argentina e na Bolívia, reforçam a estratégia de buscar liderança na América Latina como empresa integrada de energia" (PETROBRÁS, 2005, p. 60).

Em vista do projeto de expansão regional, a Petrobrás investiu maciçamente na Argentina. Mas por que a Argentina? Por que não um outro país do continente? Segundo o assessor do Presidente da Petrobrás, André Ghirardi (2007-2008)², uma das razões para se ter elegido a Argentina como base da "ampliação dos horizontes de crescimento além do mercado brasileiro" foi a importância do país vizinho na economia regional. De fato, a Argentina é o segundo maior mercado de derivados da América do Sul (PETROBRÁs, 2002, p. 39), além de possuir a terceira maior reserva provada de petróleo do continente, em 2001 (3 bilhões de barris), perdendo apenas para a Venezuela

\footnotetext{
2 Em entrevista cedida por correio eletrônico, no dia 19 de novembro de 2007 (GHIRARDI, 2007).
}

(77,7 bilhões de barris) e para o Brasil (8,5 bilhões de barris) (AGÊNCIA NACIONAL DO PETRÓLEO, 2002). Contudo, a Argentina foi ultrapassada pelo Equador, em 2002, quando este último duplicou suas reservas de 2,1 para 4,6 bilhões de barris, indo para a quarta posição com 2,9 bilhões de barris (AGÊNCIA NACIONAL DO PETRÓLEO, 2004, p. 24). Apesar da perda de posição e da diminuição de 100 milhões de barris em suas reservas, entre 2001 e 2002, a Argentina permanece como uma das regiões mais ricas em petróleo e gás do continente.

Mas esta não é a única explicação para a escolha da Argentina como base da expansão da Petrobrás na América Latina. Entre o final de 2001 e o início de 2002, a Argentina passou por uma crise econômica e política sem precedentes. O bloqueio das contas-correntes bancárias, conhecido como corralito, gerou descontentamento generalizado e levou a uma série de protestos populares. O então Presidente da Argentina, Fernando de la Rúa, renuncia ao cargo sob pressão, em dezembro de 2001. Nomeado pelo Congresso Nacional em janeiro, Eduardo Duhalde assume o posto presidencial a fim de conduzir a transição, até que, em abril de 2003, o Governador da província de Santa Cruz, Nestor Kirchner, é eleito Presidente da República: "Na economia a situação era caótica. Nas vésperas da implantação do chamado corralito a conversibilide, com paridade de um peso para um dólar, coexistia com um nível exíguo de reservas do Banco Central e com uma dívida externa impagável. As reservas garantiam somente $25 \%$ do total de passivos do sistema (base monetária, depósitos e prazos fixos). Apenas os juros da dívida, por sua vez, representavam cerca de $50 \%$ do valor das exportações e mais de $20 \%$ do gasto público consolidado, isto é, o pior endividamento da América Latina e do mundo" (FERRER, 2006, p. 299).

A crise econômica e política por que passou o país gerou muitas incertezas com relação ao futuro, mas gerou igualmente oportunidades de negócios. Em sua edição de setembro de 2002, a revista especializada no setor energético, Brasil Energia, publica uma matéria sobre a compra da Petrolera Santa Fe pela Petrobrás, intitulada "Um Negócio da China” (2002, p. 152). Numa operação de US\$ 89,55 milhões de dólares, a Petrobrás pagou cerca de um dólar por cada barril de óleo equivalente das reservas da empresa. 
Essa não foi, contudo, a única boa oportunidade de negócios encontrada pela Petrobrás durante o mesmo período. A consultoria britânica Wood Mackenzie avaliou a operação de compra da Pérez Compac, em 2002, como "um negócio comercial muito interessante" (ibidem). Os analistas da agência ressaltam que "[...] a grave situação econômica argentina torna difícil a avaliação dos preços dos ativos naquele país. Mas [...] houve um bom desconto em relação ao preço da Pérez Compac há um ou dois anos" (ibidem). Segundo o ex-Presidente da Petrobrás, Francisco Gros (2002), “[...] a aquisição da Pérez Compac, estabelecida no Planejamento Estratégico apenas para 2005, [...] viabiliza e aproxima o alcance dos objetivos estratégicos de internacionalização" (PETROBRÁS, 2003a, p. 6). As dificuldades financeiras pelas quais passavam a companhia argentina tornavam o negócio favorável à Petrobrás: “A aquisição foi realizada em um contexto no qual o grupo argentino se encontrava fortemente endividado e, conforme relatado pelos meios de comunicação, a operação teria implicado para a brasileira o ônus de uma dívida de cerca de US\$ 2 bilhões, que a desvalorização do peso argentino teria tornado impagável para o grupo [Compac]" (BIANCO, MOLDOVAN \& PORTA, 2008, p. 45).

Além destes motivos, a Argentina oferecia vantagens institucionais. Apesar da crise e, portanto, das incertezas sobre o futuro do país, o quadro regulatório do setor de petróleo e gás era atrativo. Isso ia de encontro com as metas da Petrobrás, que "definiu que sua expansão se concentraria na América do Sul, pelas avaliações estratégicas, afinidades culturais e facilidades logísticas” (PETROBRÁS, 2004, p. 10).

A reforma do setor de petróleo e gás na Argentina ocorreu antes do que no Brasil, e de forma mais profunda. Os primeiros passos para o processo de desregulação do setor ocorreram mesmo antes do Plano de Conversibilidade, com três decretos do poder Executivo promulgados no final de 1989 (1 055/89, 1 212/89 e 1 589/89). Esses decretos fixaram, conjuntamente, os princípios da reforma do setor de petróleo e gás na Argentina, especialmente no que diz respeito à captação de investimentos ao longo prazo. Tais princípios são: (i) livre disponibilidade do petróleo extraído; (ii) disponibilidade de 70\% das divisas de exportação; (iii) livre importação de petróleo e derivados sem tarifas de importação; (iv) concessões de exploração ao setor privado, licitação de áreas marginais e centrais; e (vii) equiparação dos preços nacionais e internacionais (KOZULJ, 2002, p. 16; MONTAMAT, 2007, p. 30-31).

Esse quadro encaixa-se no que Dunning chama de "vantagens institucionais de localização". Esse conceito é incorporado à teoria eclética, como forma de atualizá-la e adaptá-la ao contexto da globalização (DUNNING, 2006, p. 180). O paradigma eclético, como é chamada a teoria de Dunning, consiste em um conjunto de proposições que procuram explicar os fatores que levam as companhias a investir no exterior, os quais são definidos em termos de vantagens, intrínsecas às empresas ou ao local. Tais vantagens permitem que as companhias tenham oportunidade de explorar outros mercados e dividem-se em três tipos: vantagens de propriedade; vantagens de localização e vantagens de internalização. O primeiro tipo diz respeito às vantagens da própria empresa, como posse de patentes, conhecimento tecnológico e capital. O segundo está relacionado às vantagens oferecidas pelo país hospedeiro, tais como disponibilidade de recursos naturais, infraestrutura adequada, e mão-de-obra barata. Já o terceiro tipo de vantagem tem a ver com o modo como a empresa organiza-se a fim de otimizar os benefícios do mercado local, tais como estabilidade de preços, controle de mercado e domínio de tecnologia. Essas vantagens levam as companhias a investir em quatro modalidades, quais sejam: busca de mercados, busca de recursos naturais, busca de ativos estratégicos, e busca de eficiência.

Em seu artigo de 2006, Dunning incorpora no arcabouço do paradigma eclético as novas teorias do desenvolvimento, formuladas no contexto da globalização. A partir da leitura de três economistas contemporâneos, contestadores das visões tradicionais de desenvolvimento - Joseph Stiglitz, Amartya Sen e Douglass North -, Dunning enfatiza a importância das vantagens institucionais como determinantes dos investimentos no exterior. Segundo a definição de North, o conceito de "instituições” pode ser definido de três maneiras: em termos de regras formais, regras informais, e mecanismos de incentivos. As regras formais envolvem a legislação e o marco regulatório, as regras informais estão relacionadas a convenções, códigos de conduta, normas éticas, enfim, às regras que norteiam o comportamento humano. Já os mecanismos de incentivo dizem respeito ao conjunto de ações governamentais que podem 
estimular ou inibir determinados procedimentos ou objetivos, como, por exemplo, a capacidade de retaliar, sancionar ou de ceder benefícios fiscais e financeiros (North apud DUNNING, 2006, p. 187-188).

Levando em conta os aspectos institucionais do desenvolvimento, Dunning (2006) formula o conceito de "vantagens institucionais", que se divide em três tipos, conforme o paradigma eclético: as vantagens institucionais de propriedade, as vantagens institucionais de localização e as vantagens institucionais de internalização. Em outras palavras, quando uma empresa decide investir em outro país, ela avalia, ceteris paribus, os aspectos institucionais envolvidos.

No caso argentino, o país dispunha de vantagens institucionais de localização. O país possui o marco regulatório de petróleo e gás mais liberal da América do Sul, com grande predomínio do setor privado em todas as etapas da cadeia produtiva. O setor de petróleo e gás na Argentina foi um dos primeiros a ser reorganizado com as reformas econômicas realizadas no país durante a década de 1990, na era do Presidente Carlos Menem. O marco regulatório começa a ser delineado com a entrada em vigor das leis de Reforma do Estado (Lei n. 23 696) e de Emergência Econômica (Lei n. 23 697), ambas promulgadas no final de 1989. A primeira previa concessões e associações nas áreas e exploração e produção, enquanto a segunda acabava com os subsídios do Estado e com o Fundo Nacional de Energia; fixava preços oficiais para a venda de combustíveis e determinava porcentagens para pagamento de impostos.

Dando continuidade à reforma, foram sancionados, logo em seguida, três decretos que, em conjunto, estabeleciam o marco regulatório do setor. O Decreto 1 055, publicado no dia 10 de agosto de 1989, tinha como objetivo principal a desregulamentação da indústria de hidrocarbonetos na Argentina, tendo como pilar central o princípio da livre disponibilidade, que permitia às companhias exportar o petróleo e o gás natural produzidos no país: "A política do Governo Nacional em matéria de hidrocarbonetos se baseia na desregulamentação progressiva e integral da atividade, que conduza à efetiva e livre concorrência em todos os seguimentos no menor tempo possível, refletindo os valores internacionais, devendo em conseqüência conceder a livre disponibilidade da produção [...], tanto no mercado interno quan- to para eventual exportação dos produtos” (ARGENTINA. Presidencia de la Nación, 1989a).

No dia 8 de novembro de 1989, é sancionado o Decreto n. 1 212, o qual complementa o Decreto anterior ao estabelecer um conjunto de normas que substituem o papel do Estado no setor pelas regras de mercado, tendo como princípio a desregulamentação (Art. $1^{\circ}$ ); a concorrência (Art. $2^{\circ}$ ); a livre disponibilidade (Art. $4^{\circ}$ ); a livre importação e exportação (Art. $6^{\circ}$ ); e a liberdade de preços $\left(\right.$ Art. $\left.9^{\circ}\right)$. Em acréscimo à livre disponibilidade da produção, o Decreto n. 1 589, que entrou em vigor no dia 27 de dezembro de 1989, prevê a livre disponibilidade de divisas, fixando um teto de $70 \%$ para cada operação, além de autorizar a livre importação e exportação de hidrocarbonetos, isentando-os de taxas. O poder público limitarse-ia a exigir um aviso prévio de 12 meses antes da exportação do óleo bruto (ARGENTINA. Presidencia de la Nación, 1989b).

Este conjunto de normas definiu a política argentina para o setor de petróleo e gás. Essas reformas apresentam características bastante distintas daquelas ocorridas no Brasil. Primeiramente, as reformas na Argentina ocorreram de forma muito mais prematura. A reboque das reformas econômicas realizadas ainda no final de 1989 pelo governo Menem, o marco legislativo do setor de petróleo e gás atuou como carro-chefe das reformas setoriais na Argentina. Chama a atenção o fato de que as reformas do setor de petróleo e gás tenham sido postas em prática antes do Plano de Conversibilidade, que só entrou em vigor no dia $1^{\circ}$ de abril de 1991 . O ex-Secretário de Energia (1999-2000) e ex-Presidente da YPF (1987-1989), Daniel Montamat (2007, p. 29), sustenta que o Plano de Conversibilidade durou tanto tempo em virtude das reformas microeconômicas, a exemplo da reforma do setor de petróleo e gás, terem sido executadas antes da reforma monetária.

O ambiente normativo do setor de petróleo e gás na Argentina mostra-se mais liberal do que no Brasil. Além da grande desregulamentação (o que pode ser avaliado pelo fato de não existir um órgão regulador, como é o caso da ANP no Brasil), suas regras dão ênfase ao setor privado, o que se comprova pela privatização da Yacimientos Petrolíferos Fiscales (YPF), a então estatal petrolífera argentina, e da Gas del Estado, a empresa pública de gás. 
Antes das reformas, a indústria de petróleo e gás na Argentina era formada por duas grandes estatais: a YPF, que atuava em todas as etapas da cadeia produtiva de petróleo e derivados; e a Gas del Estado, responsável pelo transporte e pela distribuição do gás produzido pela YPF. Após a aprovação do conjunto de leis e decretos que fixaram as novas regras, o próximo passo das reformas do setor foi a privatização das duas empresas estatais.

Havia duas propostas para a privatização da YPF. A primeira era desmembrá-la em várias empresas privadas e a segunda era transformá-la em uma única grande empresa privada. Acabou prevalecendo a segunda alternativa (idem, p. 31). O processo de privatização da estatal argentina passou por várias etapas. Os Decretos n. 1757 e n. 2 778, ambos de 1990, determinam a conversão da YPF em sociedade anônima, a partir de janeiro de 1991, "definindo as linhas de ação para a privatização, prevendo a venda de ativos e associações com o [setor] privado em atividades upstream (exploração e produção) e downstream (refino, transporte e comercialização)" (ORTIZ, 2007, p. 6). O Decreto n. 2 408, sancionado no dia 12 de novembro de 1991, define o cronograma das privatizações para o setor. Em 1993, cerca de 45\% das ações da YPF são vendidas nas bolsas de Buenos Aires e de Nova York, rendendo ao erário argentino US\$ 3 bilhões em pagamento efetivo e US\$1,2 bilhão em títulos da dívida pública (KOZULJ, 2002, p. 18). Após esta operação, 20\% das ações, incluindo as ações de ouro (com direito a voto), ficaram com o Estado nacional, $12 \%$ com as províncias, $10 \%$ com os funcionários da YPF, $12 \%$ com o sistema previdenciário e $46 \%$ com o setor privado (ibidem). Conforme os funcionários saíam da empresa, vendiam suas ações, o que alterava, paulatinamente, sua configuração acionária. Entre 1994 e 1995, a YPF adquiriu 88,5\% da empresa Maxus, tornando-se presente em cinco países da América do Sul (Equador, Bolívia, Colômbia, Peru e Venezuela). Essa operação, contudo, foi realizada às custas do aumento de sua dívida.

A última etapa do processo de privatização da YPF acontece quando ela é comprada pela petroleira espanhola Repsol. Esse processo ocorre em duas fases. Primeiramente, o Estado Nacional vende $15 \%$ de sua participação acionária à empresa espanhola, ficando apenas com 5\%. No final de 1999, a Repsol compra 83\% das ações da
YPF, tornando-se então acionista majoritária. O Estado argentino permanece com as golden share, os funcionários ficam com $0,4 \%$, o setor privado com 1,4\% e a Repsol com 98,2\% (KOZULJ, 2002, p. 20).

O Decreto n. 48, de 1991, prevê a privatização da Gas del Estado, que ocorre efetivamente em 1992 (idem, p. 14). Com a venda das duas empresas estatais, completa-se o processo de privatização do setor de petróleo e gás na Argentina. Inicialmente, as privatizações estimularam o surgimento de empresas nacionais independentes.

Durante a primeira metade da década de 1990, havia várias empresas privadas argentinas que atuavam no setor, entre elas Pérez Compac (então maior petroleira independente da América Latina), Astra, Bridas, Pluspetrol e Cia. Generale de Combustibles. A partir da segunda metade dessa década, até a primeira metade da seguinte, o setor de petróleo e gás passou por um profundo processo de desnacionalização. Esse processo tem início com a venda das estatais. Em seguida, as empresas nacionais de capital privado são aos poucos adquiridas por companhias estrangeiras. Além da YPF, a Repsol adquiriu duas companhias nacionais independentes: a Astra, em 1996, e a Pluspetrol, em 1997. Em dezembro de 2000, a petroleira espanhola unifica seus ativos por meio da fusão de todas as companhias controladas por ela, criando a Repsol YPF. Ainda em 1997, a Amoco Argentina Oil, filial da British Petroleum, adquiriu os ativos da companhia independente argentina Bridas, então propriedade da família Bulgheroni, formando a companhia Panamerican Energy. Em 1999, a companhia petrolífera americana Chevron adquire a Petrolera San Jorge (CAMPODÓNICO, 2004, p. 25). Finalmente, entre 1999 e 2002, a Petrobrás cria, por meio de uma joint venture com a Dow Chemical e a Repsol YPF, a companhia binacional Mega; realiza troca de ativos com a Repsol, adquirindo a EG3 (que incluía uma refinaria e cerca de 700 postos de gasolina); compra a Petrolera Santa Fe e adquire a companhia independente Pérez Compac.

Com a criação da Petrobrás Energía S.A., por meio da fusão de seus ativos no país vizinho, a estatal brasileira torna-se a segunda maior empresa petrolífera da Argentina, com $12 \%$ da produção e 14\% das reservas de petróleo (idem, p. 26), além de atuar em todos os segmentos do setor energético. 
Em suma, do ponto de vista das regras formais, a Argentina proporcionava um ambiente institucional favorável aos investimentos estrangeiros. Desde o início do projeto de reforma do setor, a idéia central era de internacionalizá-lo, permitindo a entrada e saída de empresas estrangeiras e expondo o mercado interno ao mercado internacional. Espera-se com isso diminuir o custo de negócios, abrindo oportunidades para a exportação de gás e petróleo (MONTAMAT, 2007, p. 60).

A prioridade das reformas no setor de petróleo e gás teve motivações macroeconômicas. Os princípios da livre disponibilidade e da livre importação e exportação tinham em vista a obtenção de divisas, necessárias para a viabilidade do Plano de Conversibilidade. Com a venda das estatais, e posteriormente com as aquisições e fusões de empresas privadas nacionais, cerca de US\$ 29 bilhões foram investidos no setor de petróleo e gás, entre 1992 e 2004, o que representa 34\% do total de investimentos diretos realizados na Argentina durante o mesmo período (ORTIZ, 2007, p. 11). Mas é com o comércio exterior que o setor poderia render divisas ao longo prazo. Na primeira metade da década de 1990, o valor das exportações de petróleo mais do que decuplicou, passando de US\$ 1,2 bilhão, em 1991, quando entram em vigor as novas regras para o setor, para US\$ 14,3 bilhões, em 1995. Em 1997, as exportações de petróleo atingem o valor mais alto da década, proporcionando à economia argentina US\$ 17,1 bilhões em divisas (CAMPODÓNICO, 2004, p. 32). Os principais compradores do óleo bruto argentino são Chile e Brasil. Cerca de 75\% das exportações do petróleo produzido na Argentina, em 2000, destinaram-se a esses dois países - 44\% para o Chile e $31 \%$ para o Brasil (idem, p. 30): "[De fato], tanto durante a vigência da conversibilidade, como durante a desvalorização e a crise econômica de 2001/2002, as empresas de petróleo e gás estavam entre as maiores exportadoras do país” (ORTIZ, 2007, p. 14).

Ao garantir a livre disponibilidade e a livre exportação de petróleo e gás (no caso do gás, até $69 \%$ da produção) ${ }^{3}$, o governo argentino incentivava as transnacionais petroleiras com sede no país a investirem no setor, sobretudo quando se considera que $70 \%$ das divisas obtidas com as

\footnotetext{
3 Kozulj (2000, p. 17).
}

vendas no exterior podiam ser repatriadas. Esse marco institucional fornecia vantagens comparativas que, em acréscimo às outras motivações acima apontadas, tornavam a Argentina um país atraente, e mesmo estratégico para a Petrobrás. Foi em vista dessas razões que a estatal brasileira fez grandes investimentos no país vizinho, tornando-o o principal destino de suas atividades no exterior, entre 2000 e 2005, tanto no upstream quanto no downstream.

\section{CONSIDERAÇÕES FINAIS}

Além de atender às metas de internacionalização, os investimentos da Petrobrás na Argentina permitiram acentuar a "integração vertical de suas atividades na região”, principalmente após a aquisição da Pérez Compac (CAMPODÓNICO, 2004, p. 32). As exportações do petróleo produzido na Argentina para o Brasil saltaram de 2,3 milhões de barris, em 1992, para mais de 50 milhões, em 1997 (AGÊNCIA NACIONAL DO PETRÓLEO, 2004, p. 55). Esse aumento surpreendente ocorre justamente após as reformas do setor de petróleo e gás na Argentina. Em 1999, 14\% das importações brasileiras de petróleo vinham de lá (AGÊNCIA NACIONAL DO PETRÓLEO, 2000, p. 36).

Entretanto, como resposta à crise política e econômica de 2001-2002, o governo nacional argentino declara emergência pública, por meio da Lei n. 25 561, de janeiro de 2002, a qual “delega ao Poder Executivo a faculdade de poderes em temas relacionados ao re-ordenamento financeiro, à reativação da economia e ao crescimento econômico (CAMPODÓNICO, 2004, p. 23). Nesse contexto, é sancionado, no dia 13 de fevereiro do mesmo ano, o Decreto n. 310, que fixa um imposto de até $20 \%$ sobre as exportações de petróleo e $5 \%$ sobre as exportações de gás. O governo nacional compromete-se, contudo, a manter a livre disponibilidade de divisas em até 70\% (ibidem). Em resposta a essa política, as importações brasileiras do petróleo argentino diminuem. Em 2000, o Brasil importou 34,5 milhões de barris da Argentina, passando para 20,6 milhões, em 2001, e 12,9 milhões, em 2002 (AGÊNCIA NACIONAL DO PETRÓLEO, 2004, p. 95), o que significa que o volume importado caiu para menos da metade durante esse período.

Por outro lado, a partir de 2000, o Brasil passou a exportar óleo bruto para a Argentina, passando de 437 mil barris, nesse ano, para mais de 
5 milhões no ano seguinte, representando um aumento de mais de $1000 \%$ (idem, p. 100). Concomitantemente, o Brasil importou da Argentina, entre 2001 e 2002, em média 3,6 milhões de metros cúbicos de derivados de petróleo. Apesar das medidas tomadas pelo governo argentino para enfrentar a crise, esses dados apontam para um incremento no comércio intra-regional de petróleo e derivados, o que coincide com a orientação da estatal brasileira de integrar seus ativos em nível regional. Segundo seu relatório de 2002, a empresa tem como objetivo a "otimização do fluxo entre Brasil e Argentina; promover sinergias entre os ativos da petroquímica no Cone Sul; e atuar em todos os elos da cadeia produtiva, no Brasil e demais países do Cone Sul, de forma integrada com as demais unidades da companhia” (PETROBRÁS, 2003a, p. 18-20). Com a criação da Petrobrás Energía S.A. (PESA), a petroleira brasileira consolida e regionalização de suas atividades. Conforme reconheceu o assessor da Presidência da estatal, André Ghirardi (2007-2008), a integração regional das atividades da empresa faz parte do processo de internacionalização da Petrobrás, ressaltando que sua atuação na Argentina contribui para o "aprofundamento da gestão conjunta dos interesses de ambos os países em torno da indústria de energia” (GHIRARDI, 2007).

A América do Sul foi o primeiro passo para o processo de transformação da Petrobrás em companhia transnacional. Em 2005, ela era a $14^{\mathrm{a}}$ maior empresa petrolífera do mundo, segundo os critérios do periódico especializado Petroleum Intelligence Weekly (PETROBRÁS, 2006, p. 3). Nesse sentido, os investimentos realizados pela Petrobrás na Argentina, entre 1999 e 2005, foram um divisor de águas na história de sua atuação no exterior.

Pablo Gabriel Ferreira (ferreirarj@yahoo.com.br) é Doutorando em Ciência Política pela Université du Québec à Montréal.

BIANCO, C.; MOLDOVAN, P. \& PORTA, F. 2008. La Internacionalización de las Empresas Brasileñas en Argentina. Santiago : CEPAL.

CAMPODÓNICO, H. 2004. Reformas e Inversión en la Industria de Hidrocarburos de América Latina. Santiago : CEPAL.

DUNNING, J. H. 2006. Towards a New Paradigm of Development : Implications for the Determinants of Internationals Business. Transnational Corporations, Genebra, v. 15, n. 1, p. 173-227, Apr. Disponível em : http:// w w w. u n c t a d . org / e n / d o c s / iteiit20061a7_en.pdf. Acesso em : 10.abr.2009.

FERRER. A. 2006. A economia argentina. De suas origens ao início do século XXI. Rio de Janeiro : Elsevier.

GHIRARDI, A. 2007. Entrevista cedida ao autor por correio eletrônico, 19.nov.
HERZ, M. \& HOFFMANN, A. R. 2004. Organizações Internacionais. História e Práticas. Rio de Janeiro : Elsevier.

KOZULJ, R. 2000. Resultados de la Reestruturación de la Industria del Gas en la Argentina. Santiago : CEPAL.

2002. Balance de la Privatización de la Industria Petrolera en Argentina e su Inpacto sobre las Inversiones y la Competencia en los Mercados Minoristas en Combustibles. Santiago : CEPAL.

MONTAMAT, D. G. 2007. La Energía Argentina. Buenos Aires : El Ateneo.

ORTIZ, R. 2007. Las Empresas Transnacionales en el Sector Petrolero Argentino. Agotamiento de los Recursos Naturales, Comportamiento Oligopólico e Irresponsabilidad SócioAmbiental. Cuadernos de Investigation, n. 2. Buenos Aires : FOCO.

\section{OUTRAS FONTES}

AGÊNCIA NACIONAL DO PETRÓLEO. 2000. Anuário Estatístico da Indústria do Petróleo 1990/1999. Rio de Janeiro : ANP.
2002. Anuário Estatístico Brasileiro do Petróleo e do Gás Natural 2002. Rio de Janeiro : ANP. 
2004. Anuário Estatístico Brasileiro do Petróleo e do Gás Natural 2004. Rio de Janeiro : ANP.

ARGENTINA. Presidencia de la Nación. 1989a. Decreto n. 1 055, de 10 de outubro de 1989. Boletin oficial de la Republica Argentina, Buenos Aires, 10.out.

1989b. Decreto n. 1 212, de 8 de novembro de 1989. Boletin oficial de la Republica Argentina, Buenos Aires, 8.nov.

BRASIL. Presidência da República. 1997. Lei n. 9 478, de 6 de agosto de 1997. Dispõe sobre a política energética nacional, as atividades relativas ao monopólio do petróleo, institui o Conselho Nacional de Política Energética e a Agência Nacional do Petróleo e dá outras providências. Diário oficial da União, Brasília, 7.ago.

BRASIL ENERGIA. 1996. Brasil Energia, Rio de Janeiro, jul.

1997. Brasil Energia, Rio de Janeiro, nov. 1998. Brasil Energia, Rio de Janeiro, fev. 1999a. Brasil Energia, Rio de Janeiro, jun. . 1999b. Brasil Energia, Rio de Janeiro, jun. 1999c. Brasil Energia, Rio de Janeiro, maio.

2000. Brasil Energia, Rio de Janeiro, jul. 2003. Brasil Energia, Rio de Janeiro, jun.

COMISSÃO ECONÔMICA PARAAMÉRICA LATINA E CARIBE. 2005. La Inversión Extranjera en America Latina y Caribe. San Tiago : CEPAL.

PETROBRÁs S.A. 1987. Relatório anual. Rio de Janeiro : Petrobrás.
1991. Relatório anual. Rio de Janeiro : Petrobrás.

. 1994. Relatório anual. Rio de Janeiro : Petrobrás.

1998. Relatório anual. Rio de Janeiro : Petrobrás.

2000. Relatório anual. Rio de Janeiro : Petrobrás.

2001. Relatório anual. Rio de Janeiro : Petrobrás.

2002. Relatório anual. Rio de Janeiro : Petrobrás.

2003a. Relatório anual. Rio de Janeiro : Petrobrás.

2003b. Informações Financeiras Submetidas à Comissão de Valores Mobiliários (CVM). Informativo Anual 2002. Disponível em : http://petrobrasri.infoinvest.com.br/ modulos/relatorios_cvm.asp?language $=$ ptb\&\&x=/relatorios_cvm.asp. Acesso em 10.abr.2009:

2004. Relatório anual. Rio de Janeiro : Petrobrás.

2005. Relatório anual. Rio de Janeiro : Petrobrás.

2006. Relatório anual. Rio de Janeiro : Petrobrás.

PETROBRÁS ENERGíA S.A. 2006. Memoria, Reseña Informativa y Estados Contables al 31 Deciebre 2005, 2004, 2003 juntamente con el Informe del Auditor e Informe de la Comisión Fiscalizadora. Buenos Aires : Petrobrás Energía S.A.

Um negócio da China. 2002. Brasil Energia, Rio de Janeiro, set. 

ARGENTINA

\section{Pablo Gabriel Ferreira}

The consolidation of Petrobrás as a transnational company occurred at a moment in which the internationalization of Brazilian firms was intensified. One of the characteristics of international investment in developing countries is their concentration within their own regions. This is the Brazilian case, in which an important part of foreign investments has been devoted to South America, and to Argentina in particular - where Brazil has today become one of the major foreign investors. Petrobrás Energia S/A, a subsidiary of the state-owned Brazilian company and the second largest petroleum company in the neighboring country, became an important economic actor with activities in all segments of the energy sector.. The goal of this article is to analyze Petrobrás investments in Argentina between the years 2000 and 2005, the context in which they took place and what motivation lay behind them. For these purposes, we evaluate the relationship between the processes of the firm's internationalization and reforms in gas and petroleum sectors in both countries. We have been able to ascertain that institutional advantages of locality encouraged Petrobrás to choose Argentina as a base for its activities in the region: from the point of view of formal rules, the country furnished a favorable institutional environment for foreign investment, since from the upstart reform projects for the Argentine gas and petroleum sector were based on the idea that it should be internationalized, allowing for the entrance and exit of foreign firms and exposing the internal market to the international one.

KEYWORDS: International Political Economy; transnational companies; Petrobrás; reforms in the petroleum and gas sectors; Brazil-Argentine relations. 

BRÉSIL ET EN ARGENTINE

\section{Pablo Gabriel Ferreira}

La consolidation de Petrobrás en tant que compagnie transnationale a lieu dans un moment d'intensification du processus d'internationalisation des entreprises brésiliennes. L'une des caractéristiques des investissements internationaux des pays en développement est qu'ils se concentrent dans leur propre région. C’est le cas du Brésil qui attribue une part importante de ses investissments à l'étranger à l'Amérique du sud, surtout en Argentine où le Brésil est devenu l'un des plus grands investisseurs étrangers. Petrobrás Energía S.A., filiale de l'entreprise publique brésilienne et deuxième entreprise pétrolière la plus importante, est devenue un acteur important avec des activités dans tous les segments du secteur énergétique. L'objectif de cet article est d'analyser les investissements de Petrobrás en Argentine, entre 2000 et 2005, son contexte et ses motivations. A cet effet, nous évaluerons la relation entre le processus d'internationalisation de l'entreprise et les réformes du secteur du pétrole et du gas dans les deux pays. Nous constatons que les avantages institutionnels de localisation ont motivé Petrobrás à choisir l'Argentine comme la base de ses activités dans la région : du point de vue des règles formelles, le pays offrait un cadre favorable aux investissements étrangers, puisque dès le début du projet de réforme du secteur du pétrole et du gas argentin, l'idée essentielle était de l'internationaliser, tout en permettant l'entrée et le départ d'entreprises étrangères et en exposant le marché intérieur au marché international ;

MOTS-CLÉS : Économie Politique internationale ; entreprises transnationales ; Petrobrás ; réformes du secteur du pétrole et du gas ; relations Brésil-Argentine. 